\title{
Design of a twelve-bar planar mechanism for finger orthosis
}

\author{
Diseño de un mecanismo planar de doce barras para órtesis de dedo
}

\author{
J. C. Díaz Montes', A. H. Vilchis-González², J. C. Ávila Vilchis² \\ 'CONACYT-Facultad de Ingeniería, Universidad Autónoma del Estado de México \\ ²Facultad de Ingeniería, Universidad Autónoma del Estado de México
}

\begin{abstract}
In the last years, a considerable number of patients with hand mobility problems has been reported; in most of these cases, the patients must spend time in a specialized center to carry out a therapy to rehabilitate damaged parts. This paper presents the design of an orthosis for finger rehabilitation. The novelty of this proposal is that the design is formed by rigid links and three semicircular sliders with a center of rotation coincident with the finger joints; moreover, the synthesis of these sliders is realized in a new and simple way. The mechanism is designed to be compact enough to be used by a person during a whole day; it is formed by twelve links and allows the three finger phalanxes to be flexed simultaneously. The mechanism is coupled only to the dorsal side of the hand and has no interference when grasping objects, in such a way that the orthosis presented in this paper enables the patient to perform the Activities of Daily Living. The synthesis of the mechanism presented in this paper focuses on the middle finger, nevertheless, it is possible to use the same configuration for the others fingers only by scaling.
\end{abstract}

KEYwORDS: Hand Rehabilitation; Mechanical Design; Mechanisms Synthesis; Orthosis Finger; Semicircular Slider. 


\section{RESUMEN}

En los últimos años un considerable número de pacientes con problemas de movilidad en las manos ha sido reportado; en la mayoría de los casos, los pacientes deben pasar un tiempo determinado en un centro especializado para llevar a cabo una terapia para rehabilitar las partes afectadas. En este artículo se presenta el diseño de una ortesis para rehabilitación de un dedo. La novedad de esta propuesta es que el diseño está formado por eslabones rígidos y tres correderas semicirculares, cuyo centro de rotación coincide con el centro de rotación de los dedos; además, la síntesis de estas correderas se realizó de una manera sencilla y nueva. El mecanismo diseñado es suficientemente compacto para ser utilizado por una persona durante un día entero; está formado por doce eslabones y permite que las tres falanges se muevan simultáneamente. El mecanismo es acoplado al dorso de la mano para no interferir con la sujeción de objetos, y por tanto permitir el desarrollo de las actividades de la vida diaria. La síntesis del mecanismo presentada en este artículo se enfoca en el dedo medio, sin embargo es posible usar la misma configuración para los otros dedos, solo escalando el mecanismo.

PALABRAS CLAVE: Rehabilitación de mano, diseño mecánico, síntesis de mecanismos, ortesis de dedo, corredera semicircular.

\section{Correspondencia}

DESTINATARIO: Juan Carlos Ávila Vilchis

INSTITUCIÓN: Facultad de Ingeniería, Universidad

Autónoma del Estado de México

DIRECCIÓN: Cerro de Coatepec S/N, Tercer Piso, Edificio

G, Ciudad Universitaria, C.P. 50100, Toluca, Estado de

México, México

CORREO ELECTRÓNICO: jcavilav@uaemex.mx

\section{Fecha de recepción:}

12 de julio de 2017

Fecha de aceptación:

10 de octubre de 2017 


\section{INTRODUCTION}

One million cerebrovascular diseases were reported in Mexico in $2008^{[1]}$, most of the survivors of these cases continued to have hand mobility problems two years after the stroke ${ }^{[2]}$. In 2010 in Mexico, 5739270 persons were reported with some kind of disability, this number represented the $5.1 \%$ of total population that year ${ }^{[1]}$, some of these disabilities were caused by stroke. In 2010 in Japan more than 70,000 patients of cervical spine injury were reported ${ }^{[3]}$. In the USA in 2015, about 795 000 people had stroke ${ }^{[4]}$. In 2010, 16.9 million people worldwide had a stroke for the first time ${ }^{[4]}$. Some of the most common consequences of these disabilities are the limitation in force and mobility of the hand fingers. In general terms, people with levels smaller than 3 in the Manual Muscle Testing Grading System (MMTGS) need external help to develop the Activities of Daily Living (ADL). Level 3 in MMTGS corresponds to a full Range of Motion (ROM) against gravity and slight resistance.

Stroke survivors must follow a rehabilitation program, some of these survivors that completed their rehabilitation program for upper limbs only recovered the motor function in shoulders and wrists, but the mobility in hands and fingers was limited ${ }^{[5,6]}$. The fingers rehabilitation basically consists of actively moving the fingers and thus reactivating the muscles associated to them. The fingers can move on a 3D workspace, reached by the flexion-extension and adduction-abduction movements of the joints. In a rehabilitation protocol, usually, the adduction-abduction movement is skipped (except for the thumb), and thus it generates a $2 \mathrm{D}$ and more simple workspace, as it is pointed out by ${ }^{[7]}$.

The use of robotic devices is increasing, the motor therapy is showing a great potential, some benefits of the rehabilitation with robots include the ability to develop precise and repeatable therapeutic exercises ${ }^{[8]}$, a safe and intensive training ${ }^{[9,10]}$, a significant improvement in the behavior of the affected limbs ${ }^{[11]}$ and an intensive motor improvement in chronic stroke ${ }^{[12]}$.
Nowadays there are several devices to help in hand rehabilitation, mainly for stroke survivors. The options that we find in the literature go from training weak muscles with devices to exoskeletons than help the hand generate a bigger grip force. These devices are designed mostly for the user to spend some therapy time in a specialized place, adequate for the patient training.

Some of the designs of the rehabilitation devices are: Cybergrasp which is an exoskeleton situated on the hand dorsum, used to exert force on each individual finger, this exoskeleton is used on a robotic/virtual environment to train the hand of persons with hemiparesis ${ }^{[13]}$; Hand Mentor is a system for hand rehabilitation by active motion of all the fingers, the device provides a controlled resistive force by a pneumatic muscle ${ }^{[14]}$; the Hand Wrist Assistive Rehabilitation Device (HWARD) is actuated pneumatically, the device can flex the thumb and simultaneously the four fingers ${ }^{[11]}$; the Exoskeleton Hand Robotic Training Device is designed specially to be used by persons after stroke, it is driven by the patient muscle signals [15]; HANDEXOS is an exoskeleton for rehabilitation of the hand for patients after stroke, the device is composed by some shell structures connected by translational and rotational joints that allow the fingers flexion ${ }^{[16]}$. Others devices under development are: the orthosis designed for Patara et al. ${ }^{[17]}$ which uses one air cylinder to flex the four fingers, it is composed by a cam and a set of links; the active hand orthosis designed by Rosati et al. ${ }^{[18]}$ for the acute and sub-acute phase after stroke employs one elastic actuator to produce the force to flex the four fingers at the same time; the device proposed by Lambercy et al. ${ }^{[19]}$ is a exoskeleton thumb that can perform the flexion-extension and abduction-adduction movements using a linear servomotor; the device developed by Morogumi et al. ${ }^{\text {[3] is }}$ an orthosis to support ADL for patients with cervical spinal cord injury, the device uses a servomotor and a compression spring to open/close the four fingers; the upper limb orthosis designed by Sooraj et al. ${ }^{[20]}$ provi- 
des bi-directional haptic feedback, this orthosis is designed to improve the locomotion capability and increases the endurance through physical rehabilitation exercises; Tjahyono et al. ${ }^{[21]}$ developed a five-fingered hand exoskeleton that is driven by pneumatic muscles; the wearable exoskeleton designed by Zhang et al. ${ }^{[22]}$ uses Bowden cables to flex the three joints of two fingers in a bidirectional way; the five-fingered hand exoskeleton proposed by Sandoval-González et al. ${ }^{[23]}$ uses DC motors to flex all phalanxes individually; the robotic hand exoskeleton designed by Leonardis et al. ${ }^{[24]}$ is conceived to support stroke patients in cylindrical grasping, has two DC motors and two degree of freedom, one for the fingers and one for the thumb. All the above mentioned devices were obtained through a specific design process; however, the designers of those mechanisms do no report if they have been obtained through an optimal process.

The devices where the optimization is considered are briefly presented below: the seven-bar linkage presented on ${ }^{[25]}$ is force and kinematically synthesized, the mechanism has a semicircular slider which is used for switch between pinching or grasping tasks; exoskeleton presented on ${ }^{[26]}$ is composed by a two four-bar linkage, the mechanism is synthetized to follow a specific fingertip path; the underactuated mechanism described on ${ }^{[27,28]}$ is optimized to flex two phalanxes and enhance the force capabilities of the finger, the optimization process is based on a kinetostatic analysis; a synthesis of a six-bar linkage for a hand rehabilitation robot is detailed on ${ }^{[29]}$, the mechanism is obtained using both geometrical and body-guidance synthesis.

This paper presents an optimal mechanical design of an orthosis for finger rehabilitation; the orthosis is useful to assist the flexion-extension movement of the middle finger. The orthosis weight and volume are adequate to be used by a patient during all day (maximum $1 \mathrm{~N}$ for each finger) and thus he can rehabilitate by himself while performing the Activities of Daily
Living. The originality on the proposed mechanism is the use of rigid linkages to flex the three phalanxes at the same time, using only one degree of mobility. The mechanism is formed by sixteen joints and twelve bodies, three of them have a semicircular slider.

\section{MATERIAL AND METHODS}

\section{Design Factors}

In this work we used anthropometric data of the percentile 50 of the human hand of Mexico City's population, presented by ${ }^{[30]}$. The design factors taken into account are: the orthosis must be fixed to the dorsal side of the hand; it should not alter the flexion-extension natural movement of the finger; the orthosis should not interfere in object grasping (palmar side must be free); the orthosis must conduct each of the three phalanx through all ROM of flexion-extension using only one degree of freedom; the three joints must move at the same time; the orthosis should follow a path created by the midpoints of the dorsal-side of the middle finger (see Figure 1); the orthosis must have a weight $\mathrm{w}$ that allows it to be used by a person during a whole day of activities (for instance, $w \leq 1 \mathrm{~N}$ ). These design factors were proposed by the authors after several talks with therapists moreover considering the orthosis must be useful to perform ADL.

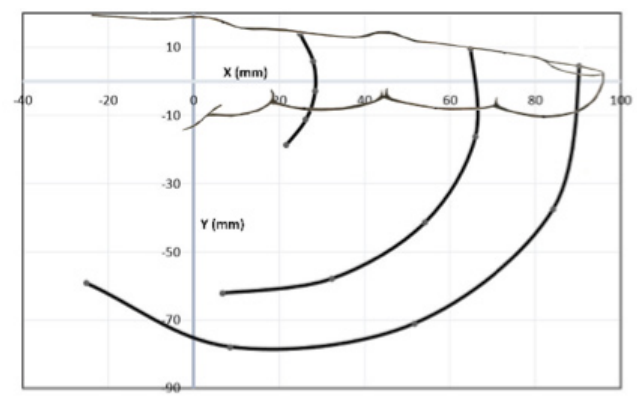

FIGURE 1. Paths of midpoints of the phalanxes.

Figure 1 shows the paths followed by the midpoints ( $\mathrm{d} 1$, h1 and $\mathrm{s} 1$ ) of the phalanxes: $\mathrm{d} 1$ corresponds to the proximal phalanx, h1 to the medial phalanx and s1 to the distal phalanx. 


\section{Mechanical Design}

The mechanism is formed by rigid links, we considered the configuration proposed by Ho et al. ${ }^{[15]}$ and we added four more links to achieve the movement of the distal phalanx. The mechanism configuration and the number of bodies (ground and posed by Suh and
Radcliffe ${ }^{[32]}$. The mechanism has twelve bodies and sixteen joints; therefore, it has one degree of freedom (DOF). System variables are shown in Figure 3, the angles $\theta_{1}$ to $\theta_{11}$ represent the angular orientation of the respective body and $\mathrm{x}_{1}$ represents the displacement of the linear actuator.

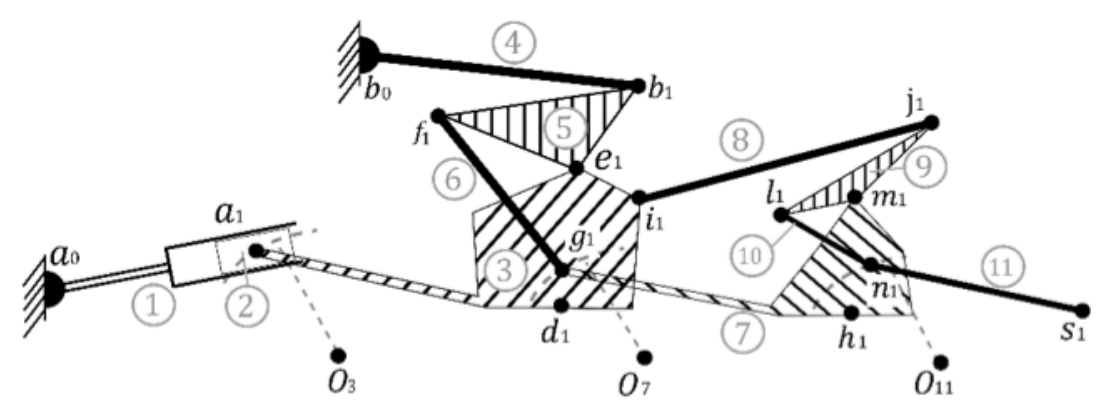

FIGURE 2. Twelve bar linkage orthosis.

\section{System Analysis}

In Figure 2, $a_{0}$ and $b_{0}$ points are fixed to the ground (a structure coupled to the dorsal side of the hand). Bodies 1 and 2 correspond to a linear actuator (which is considered like a linear slider), body 1 is the fixed part and body 2 is the moving part; all others bodies are rigid links (from body 3 to body 11). Point a_1 moves inside a slider with a semicircular path, which has a center of rotation coincident with the metacarpophalangeal joint $\left(\mathrm{O}_{3}\right.$ point); point $\mathrm{g}_{1}$ moves inside a second slider with semicircular path with center of rotation coincident with the proximal interphalangeal joint $\left(\mathrm{O}_{7}\right.$ point $)$ and $\mathrm{n}_{1}$ point does the same around the distal interphalangeal joint (with center of rotation at $\mathrm{O}_{11}$ point); $\mathrm{d}_{1}, \mathrm{~h}_{1}$ and $\mathrm{s}_{1}$ points are coupled to the dorsal part at the middle of the proximal, medial and distal phalanxes, respectively. When the actuator turns on, the mechanism moves all phalanxes at the same time.

The kinematic analysis is performed using a special case of rotational displacement matrix (2D path) proposed by Suh and Radcliffe ${ }^{\text {[32] }}$. The mechanism has twelve bodies and sixteen joints; therefore, it has one degree of freedom (DOF). System variables are shown in Figure 3, the angles $\theta_{1}$ to $\theta_{11}$ represent the angular orientation of the respective body and $\mathrm{x}_{1}$ represents the displacement of the linear actuator.

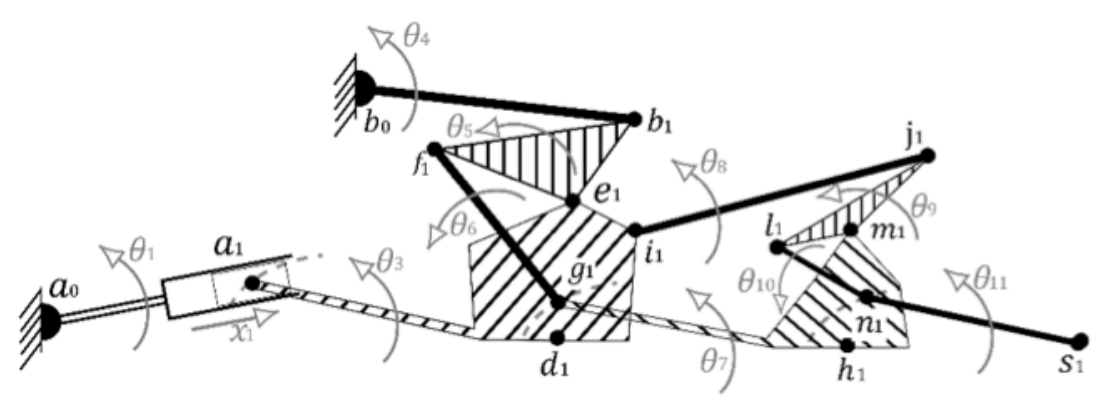

FIGURE 3. Variables used in the mechanism analysis. 


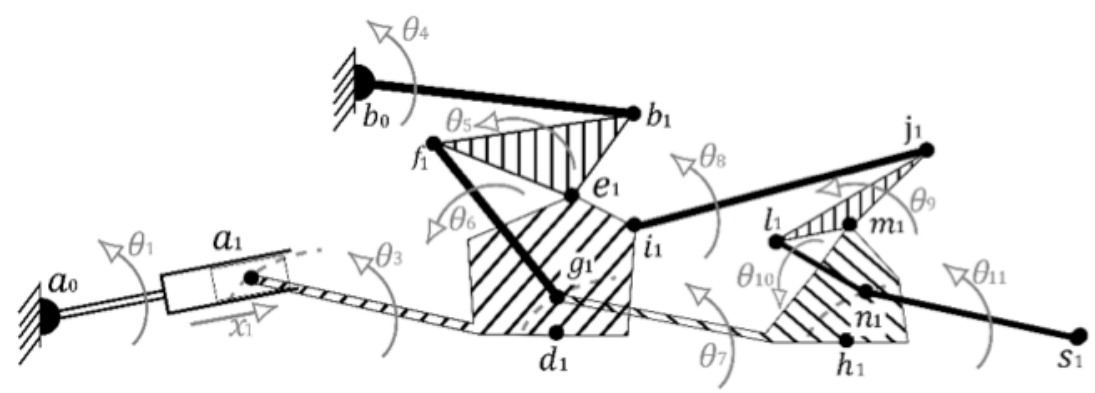

FIGURE 4. Vectors used in the kinematic analysis.

Figure 4 shows the vectors $\left(r_{-} n\right)$ associated to the mechanism at initial positions, where:

$$
\begin{array}{ll}
\mathrm{r}_{0}=\mathrm{a}_{0} & \mathrm{r}_{5 \mathrm{a}}=\mathrm{f}_{1}-\mathrm{b}_{1} \\
\mathrm{r}_{0 \mathrm{a}}=\mathrm{O}_{3} & \mathrm{r}_{6}=\mathrm{g}_{1}-\mathrm{f}_{1} \\
\mathrm{r}_{\mathrm{ob}}=\mathrm{b}_{0} & \mathrm{r}_{7}=\mathrm{g}_{1}-\mathrm{O}_{7} \\
\mathrm{r}_{1}=\mathrm{a}_{1}-\mathrm{a}_{0} & \mathrm{r}_{7 \mathrm{a}}=\mathrm{h}_{1}-\mathrm{O}_{7} \\
\mathrm{r}_{2}=\mathrm{a}_{1}-\mathrm{O}_{3} & \mathrm{r}_{7 \mathrm{~b}}=\mathrm{m}_{1}-\mathrm{O}_{7} \\
\mathrm{r}_{2 \mathrm{a}}=\mathrm{c}_{1}-\mathrm{O}_{3} & \mathrm{r}_{7 \mathrm{c}}=\mathrm{O}_{11}-\mathrm{O}_{7} \\
\mathrm{r}_{2 \mathrm{~b}}=\mathrm{O}_{7}-\mathrm{O}_{3} & \mathrm{r}_{8}=\mathrm{j}_{1}-\mathrm{i}_{1} \\
\mathrm{r}_{2 \mathrm{c}}=\mathrm{e}_{1}-\mathrm{O}_{3} & \mathrm{r}_{9}=\mathrm{m}_{1}-\mathrm{j}_{1} \\
\mathrm{r}_{2 \mathrm{~d}}=\mathrm{d}_{1}-\mathrm{O}_{3} & \mathrm{r}_{9 \mathrm{a}}=\mathrm{l}_{1}-\mathrm{j}_{1} \\
\mathrm{r}_{2 \mathrm{e}}=\mathrm{i}_{1}-\mathrm{O}_{3} & \mathrm{r}_{10}=\mathrm{r}_{1}-\mathrm{I}_{1} \\
\mathrm{r}_{4}=\mathrm{b}_{1}-\mathrm{b}_{0} & \mathrm{r}_{11}=\mathrm{n}_{1}-\mathrm{O}_{11} \\
\mathrm{r}_{5}=\mathrm{e}_{1}-\mathrm{b}_{1} & \mathrm{r}_{11 \mathrm{a}}=\mathrm{s}_{1}-\mathrm{O}_{11}
\end{array}
$$

Because the mechanism has $1 \mathrm{DOF}$ and 11 variables (according the Grübler-Kutzbach criterion), it is necessary to create 5 loop equations. Equations (1) to (5) represent the mechanism loops in any position or time. In these equations $R_{n}$ represent the vector $r_{n}$ at any time.

$$
\begin{gathered}
\boldsymbol{R}_{0}+\boldsymbol{R}_{1}-\boldsymbol{R}_{2}-\boldsymbol{R}_{0 a}=0 \\
\boldsymbol{R}_{0 b}+\boldsymbol{R}_{4}+\boldsymbol{R}_{5}-\boldsymbol{R}_{2 c}-\boldsymbol{R}_{0 a}=0 \\
\boldsymbol{R}_{2 b}+\boldsymbol{R}_{7}-\boldsymbol{R}_{6}-\boldsymbol{R}_{5 a}+\boldsymbol{R}_{5}-\boldsymbol{R}_{2 c}=0 \\
\boldsymbol{R}_{2 e}+\boldsymbol{R}_{8}+\boldsymbol{R}_{9}-\boldsymbol{R}_{7 b}-\boldsymbol{R}_{2 b}=0 \\
\boldsymbol{R}_{7 c}+\boldsymbol{R}_{11}-\boldsymbol{R}_{10}-\boldsymbol{R}_{9 a}+\boldsymbol{R}_{9}-\boldsymbol{R}_{7 b}=0
\end{gathered}
$$

In the above equations, vectors with subscript $n=$ 2,3,4,5,5a,6,7,8,9,9a,10 and 11 have only a rotational movement, therefore their position $R_{n}$ can be calculated by using the rotational displacement matrix for a $2 \mathrm{D}$ path given in equation (6).

$$
\boldsymbol{R}_{n}=\left[\begin{array}{cc}
\cos \theta_{n} & -\sin \theta_{n} \\
\sin \theta_{n} & \cos \theta_{n}
\end{array}\right] \boldsymbol{r}_{n}
$$

Vectors $r_{o}, r_{o a}$ and $r_{o b}$ do not change their positions, because they are defined between two fixed points, therefore:

$$
\begin{gathered}
\boldsymbol{R}_{0}=\boldsymbol{r}_{0} \\
\boldsymbol{R}_{0 a}=\boldsymbol{r}_{0 a} \\
\boldsymbol{R}_{0 b}=\boldsymbol{r}_{0 b}
\end{gathered}
$$

Vector $R_{1}$ has rotational and longitudinal movements, equation (10) defines its movement.

$$
\begin{gathered}
\boldsymbol{R}_{1}=\left[\begin{array}{cc}
\cos \theta_{1} & -\sin \theta_{1} \\
\sin \theta_{1} & \cos \theta_{1}
\end{array}\right] \boldsymbol{r}_{1} \\
+\left[\begin{array}{c}
r_{1 x}\left(1+{ }^{x_{1}} /\left\|\boldsymbol{r}_{1}\right\|\right. \\
\left.r_{1 y}+x_{1} \sqrt{1-\left(x^{1} /\left\|\boldsymbol{r}_{1}\right\|\right.}\right)^{2}
\end{array}\right]
\end{gathered}
$$

\section{Optimal Synthesis of Mechanism}

Besides the design factors, the synthesis includes more restrictions: the mechanism must follow the flexion-extension path of each phalanx (see Figure 1); dimensions 
of mechanism should not interfere with flexion-extension finger movement; linkages paths should not interfere with each other; mechanism must reach maximum flexion angles of each phalanx $\left(70^{\circ}, 90^{\circ}\right.$ and $50^{\circ}$ for proximal, medial and distal, respectively, based on ${ }^{[31]}$ the authors consider these values are sufficient to perform any grasp task). We establish that the mechanism must pass through five positions (control points) from a fully extended to a fully flexed position.

The synthesis of mechanism is realized using the matrix method proposed by Suh and Radcliffe [32], in which a plane displacement matrix is designated for some bodies of the mechanism; each matrix include a rotational angle, these angles are shown in Figure 5 and represent the rotation of the correspondent body. For example $\beta_{1 \mathrm{j}}$ is the angle that the body 5 (see Figure 2) generates when it moves from the position 1 to the position j. Hereinafter, subscript or superscript $\mathrm{j}$ will represent any future position. One of the advantages of this method is that the results are always in the real number space.

The synthesis of mechanism starts at point $d_{1}$ (see Figure 5), a plane displacement matrix $A_{1}^{\mathrm{j}}$ is generated using $d_{1}$ point and the rotational angle of the body 3 $\left(\alpha_{1 \mathrm{j}}\right)$. The matrix $A_{1}^{\mathrm{j}}$ is provided in (11):

$$
\begin{aligned}
& \boldsymbol{A}_{1}^{j}= \\
& {\left[\begin{array}{ccc}
\cos \alpha_{1 j} & -\sin \alpha_{1 j} & d_{j x}-\left(d_{1 x} \cos \alpha_{1 j}-d_{1 y} \sin \alpha_{1 j}\right) \\
\sin \alpha_{1 j} & \cos \alpha_{1 j} & d_{j y}-\left(d_{1 x} \operatorname{sen} \alpha_{1 j}+d_{1 y} \cos \alpha_{1 j}\right) \\
0 & 0 & 1
\end{array}\right]}
\end{aligned}
$$

In this paper all plane displacement matrices will be abbreviated as $A_{1}^{\mathrm{j}}=\mathrm{f}\left(\alpha_{1 \mathrm{j}}, \mathrm{d}_{1}, \mathrm{~d}_{\mathrm{j}}\right)$. This matrix defines the movement of the body 3 from position 1 to position $j$. After using this matrix we also know the position of any point on the body 3 , this is $\mathrm{i}_{\mathrm{j}}=A_{1}^{\mathrm{j}} i_{1}, e_{\mathrm{j}}=A_{1}^{\mathrm{j}} e_{1}, c_{\mathrm{j}}=$ $A_{1}^{\mathrm{j}} \mathrm{C}_{1}, \mathrm{O}_{7 \mathrm{j}}=A_{1}^{\mathrm{j}} \mathrm{O}_{71}$.

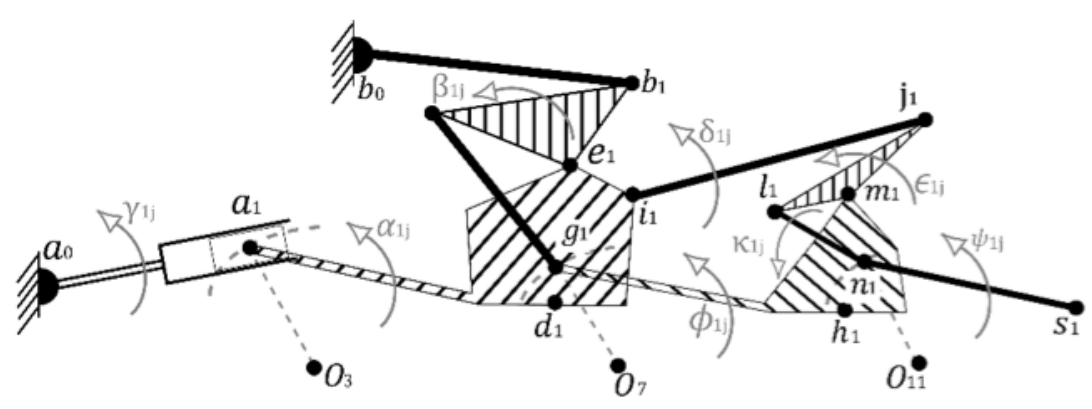

FIGURE 5. Rotational angles used in the plane displacement matrix.

Using the matrix $A_{1}^{\mathrm{j}}$ we know the $e_{\mathrm{j}}$ point, and using this point we can write a new plane displacement matrix $B_{1}^{\mathrm{j}}$ for the body 5 , where $B_{1}^{\mathrm{j}}=\mathrm{f}\left(\beta_{1 \mathrm{j}}, e_{1}, e_{\mathrm{j}}\right)$ and then calculate the points $f_{\mathrm{j}}=B_{1}^{\mathrm{j}} f_{\mathrm{j}}$ and $b_{\mathrm{j}}=B_{1}^{\mathrm{j}} b_{1}$.

Using the $i_{\mathrm{j}}$ point it is possible to create the matrix $D_{1}^{\mathrm{j}}=$ $\mathrm{f}\left(\delta_{1 \mathrm{j}}, i_{1}, i_{\mathrm{j}}\right)$ for body 8 and to know $j_{\mathrm{j}}=D_{1}^{\mathrm{j}} j_{1}$.

Following this procedure all plane displacement matrices of this mechanism are set. For the body 9, $E_{1}^{\mathrm{j}}=\mathrm{f}\left(\epsilon_{1 \mathrm{j}}, j_{1}, j_{\mathrm{j}}\right), m_{\mathrm{j}}=E_{1}^{\mathrm{j}} m_{1}, l_{\mathrm{j}}=E_{1}^{\mathrm{j}} l_{1}$; in body 7 the displacement plane matrix is $F_{1}^{\mathrm{j}}=\mathrm{f}\left(\phi_{1 \mathrm{j}}, m_{1}, m_{\mathrm{j}}\right)$ and the points can be calculated, then $h_{\mathrm{j}}=F_{1}^{\mathrm{j}} h_{1}, h_{\mathrm{j}}=F_{1}^{\mathrm{j}} g_{1}, \mathrm{O}_{11 \mathrm{j}}=F_{1}^{\mathrm{j}} \mathrm{O}_{11}$; for body $10 K_{1}^{\mathrm{j}}=\mathrm{f}\left(\kappa_{1 \mathrm{j}}, l_{1}, l_{\mathrm{j}}\right)$ and $n_{\mathrm{j}}=K_{1}^{\mathrm{j}} n_{1}$ and for the body $11 L_{1}^{\mathrm{j}}=\mathrm{f}\left(\psi_{1 \mathrm{j}}, n_{1}, n_{\mathrm{j}}\right), n_{\mathrm{j}}=L_{1}^{\mathrm{j}} S_{1}$.

Input actuator (bodies 1 and 2) has both rotational and lineal movements. Figure 6 represents the movement of the point $a_{1}$ form position 1 to position $\mathrm{j}$. The $\gamma_{1}$ angle can be calculated as $\gamma_{1}=\tan ^{-1}\left[\left(a_{1 \mathrm{y}}-a_{\mathrm{oy}}\right) /\left(a_{1 \mathrm{x}}-a_{\mathrm{ox}}\right)\right]$, the displacement plane matrix is $G_{1}^{\mathrm{j}}=\mathrm{f}\left(\gamma_{1 \mathrm{j}}, a_{0}, a_{0}\right)$ therefore the $a_{\mathrm{j}}$ point is $a_{\mathrm{j}}=G_{1}^{\mathrm{j}} a_{1}+\left[x_{1} \cos \left(\gamma_{1}+\gamma_{1 \mathrm{j}}\right) x_{1} \sin \left(\gamma_{1}+\gamma_{1 \mathrm{j}}\right)\right]$ ${ }^{T}$. In all cases (matrices and points) $j=2,3,4,5$ because the mechanism will pass through five control points. 


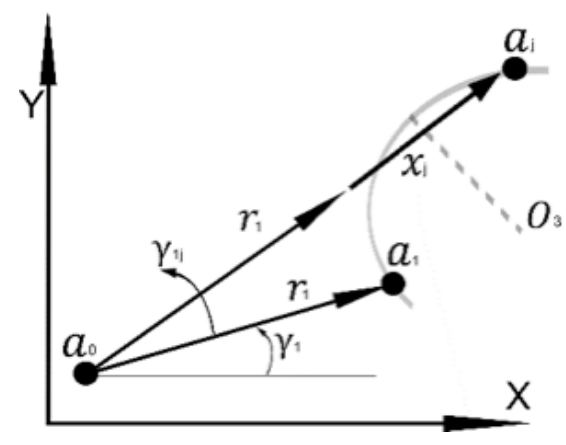

FIGURE 6. Rotational and lineal movements of point $a_{1}$.

\section{Equations for synthesis of rigid links}

Restrictions of the mechanism are provided by equation (12) that is established for rigid links; therefore, the magnitude of the distance between all points of the same body will not change during the movement of the mechanism. For example, equation $\left(f_{1}-g_{1}\right)^{\mathrm{T}}$ $\left(f_{1}-g_{1}\right)-\left(f_{i}-g_{j}\right)^{\mathrm{T}}\left(f_{\mathrm{i}}-g\right)=0$ represents the fact that the link longitude of the rigid body $\left(f_{1}-g_{1}\right)$ in the initial position is the same that longitude in position two $\left(f_{2}-g_{2}\right)$ and so on. The first objective function can be written as equation 12, where

$$
\begin{aligned}
& \chi=\left[\begin{array}{c}
a_{0}, a_{1}, b_{1}, c_{1}, d_{1}, e_{1}, f_{1}, g_{1}, h_{1}, i_{1}, l_{1}, m_{1}, n_{1}, \\
\alpha_{12}, \beta_{12}, \gamma_{12}, \delta_{12}, \varepsilon_{12}, \varphi_{12}, \phi_{12}, k_{12} \ldots \phi_{15}, k_{15}
\end{array}\right] \\
& F_{1}(\chi)=\sum_{j=2}^{5}\left\{\left[\left(f_{1}-g_{1}\right)^{T}\left(f_{1}-g_{1}\right)\right.\right. \\
&\left.-\left(f_{j}-g_{j}\right)^{T}\left(f_{j}-g_{j}\right)\right]^{2} \\
&+\left[\left(c_{1}-O_{3}\right)^{T}\left(c_{1}-O_{3}\right)\right. \\
&\left.-\left(c_{j}-O_{3}\right)^{T}\left(c_{j}-O_{3}\right)\right]^{2} \\
&+\left[\left(b_{1}-b_{0}\right)^{T}\left(b_{1}-b_{0}\right)\right. \\
&\left.-\left(b_{j}-b_{0}\right)^{T}\left(b_{j}-b_{0}\right)\right]^{2} \\
&+\left[\left(g_{1}-O_{7}\right)^{T}\left(g_{1}-O_{7}\right)\right. \\
&\left.-\left(g_{j}-O_{7 j}\right)^{T}\left(g_{j}-O_{7 j}\right)\right]^{2} \\
&+\left[\left(h_{1}-O_{11}\right)^{T}\left(h_{1}-O_{11}\right)\right. \\
&\left.-\left(h_{j}-O_{11 j}\right)^{T}\left(h_{j}-O_{11 j}\right)\right]^{2} \\
&+\left[\left(a_{1}-O_{3}\right)^{T}\left(a_{1}-O_{3}\right)\right. \\
&\left.\left.-\left(a_{j}-O_{3 j}\right)^{T}\left(a_{j}-O_{3 j}\right)\right]^{2}\right\}
\end{aligned}
$$

\section{Equations synthesis of semicircular slider}

Orthosis mechanism is formed by three sliders, each one with a semicircular path, with the center of rotation coincident with the joint of the respective phalanx (bodies 3, 7 and 11). The equation of a circumference centered at the point $\left(\mathrm{O}_{3 \mathrm{x}}, \mathrm{O}_{3 \mathrm{y}}\right)$ is used to develop an equation for the synthesis of semicircular slider for the body 3:

$$
\left(c_{x}-O_{3 x}\right)^{2}+\left(c_{y}-O_{3 y}\right)^{2}=r^{2}
$$

Due to the fact that the radius $r$ is constant during the whole slider trajectory, the equation for the $\mathrm{j}$ position is

$$
\left(c_{1}-O_{3}\right)^{T}\left(c_{1}-O_{3}\right)-\left(c_{j}-O_{3}\right)^{T}\left(c_{j}-O_{3}\right)=0
$$

The others semicircular paths (bodies 7 and 11) can be obtained in a similar way. The objective function for all semicircular sliders can be written as:

$$
\begin{gathered}
F_{2}(\chi)=\sum_{j=2}^{5}\left\{\left[\left(c_{1}-O_{3}\right)^{T}\left(c_{1}-O_{3}\right)-\right.\right. \\
\left.\left(c_{j}-O_{3}\right)^{T}\left(c_{j}-O_{3}\right)\right]^{2}+\left[\left(g_{1}-O_{71}\right)^{T}\left(g_{1}-O_{71}\right)-\right. \\
\left.\left(g_{j}-O_{7 j}\right)^{T}\left(g_{j}-O_{7 j}\right)\right]+\left[( n _ { 1 } - O _ { 1 1 1 } ) ^ { T } \left(n_{1}-\right.\right. \\
\left.\left.\left.O_{111}\right)-\left(n_{j}-O_{11 j}\right)^{T}\left(n_{j}-O_{11 j}\right)\right]^{2}\right\}
\end{gathered}
$$

\section{Additional restrictions for the synthesis}

Due to some problems of interference between adjacent links, bodies 5 and 9 need to be straight links, the equation (17) is obtained through the dot product property and are necessary to achieve such condition.

$$
\begin{aligned}
& F_{3}(\chi)=\sum_{j=2}^{5}\left\{\left[\left(\begin{array}{l}
\left(b_{1}-e_{1}\right) \cdot\left(f_{1}-e_{1}\right)+ \\
\left\|b_{1}-e_{1}\right\|\left\|f_{1}-e_{1}\right\|
\end{array}\right]^{2}+\left[\left(j_{1}-\right.\right.\right.\right. \\
& \left.\left.\left.m_{1}\right) \cdot\left(l_{1}-m_{1}\right)+\left\|j_{1}-m_{1}\right\|\left\|l_{1}-m_{1}\right\|\right]^{2}\right\}
\end{aligned}
$$

It is necessary that the mechanism reaches the maximum flexion angles $\phi$ and $\psi$ at medial and distal phalanxes, respectively. The equation (18) is established to fulfill this condition: 


$$
\begin{aligned}
& F_{4}(\chi)=\sum_{j=2}^{5}\left\{\left[\frac{\left(h_{1}-o_{7}\right) \cdot\left(h_{j}-o_{7 j}\right)}{\left\|h_{1}-o_{7}\right\|\left\|h_{j}-o_{7 j}\right\|}-\cos \phi_{j}\right]^{2}+\right. \\
& \left.\left[\frac{\left(s_{1}-o_{11}\right) \cdot\left(s_{j}-o_{11 j}\right)}{\left\|s_{1}-o_{11}\right\|\left\|s_{j}-o_{11 j}\right\|}-\cos \varphi_{j}\right]^{2}\right\}
\end{aligned}
$$

For this mechanism and its restrictions there is no exact solution; it is then necessary to perform an optimal synthesis. The global objective function $F(\chi)$ is formed by $F(\chi)=F_{1}(\chi)+F_{2}(\chi)+F_{3}(\chi)+F_{4}(\chi)$. The results presented below correspond to the solution of this Objective Function.

\section{RESULTS}

The process to find an optimal mechanical design is iterative; the synthesis equations do not guarantee that all specifications will be satisfied, because these equations do not include the interference between adjacent links or the continuity on the mechanism movement, for instance. The iterative process consists on synthesizing one mechanism, then performing a kinematic analysis and verifying that the mechanism fill all others design factors. After several iterations, the mechanism that satisfies design factors and specifications is found. The process of design the mechanism is shown in Figure 7.

Coordinates, in meters, of all points of the mechanism are presented in Table 1.

TABLE 1. Coordinates of points of the orthosis.

\begin{tabular}{|l|l|}
\hline $\mathrm{a}_{0}=(0.1000,0.0250)$ & $\mathrm{a}_{1}=(-0.0200,0.0200)$ \\
\hline $\mathrm{b}_{0}=(0.0070,0.0393)$ & $\mathrm{b}_{1}=(0.0362,0.0278)$ \\
\hline $\mathrm{c}_{1}=(-0.0140,0.0190)$ & $\mathrm{e}_{1}=(0.0132,0.0351)$ \\
\hline $\mathrm{f}_{1}=(-0.002,0.0426)$ & $\mathrm{g}_{1}=(0.0310,0.0200)$ \\
\hline $\mathrm{i}_{1}=(0.0536,0.0326)$ & $\mathrm{j}_{1}=(0.0784,0.0206)$ \\
\hline $\mathrm{l}_{1}=(0.0476,0.0266)$ & $\mathrm{m}_{1}=(0.0560,0.0251)$ \\
\hline $\mathrm{n}_{1}=(0.0740,0.0180)$ & $\mathrm{s}_{1}=(0.0906,0.0110)$ \\
\hline
\end{tabular}

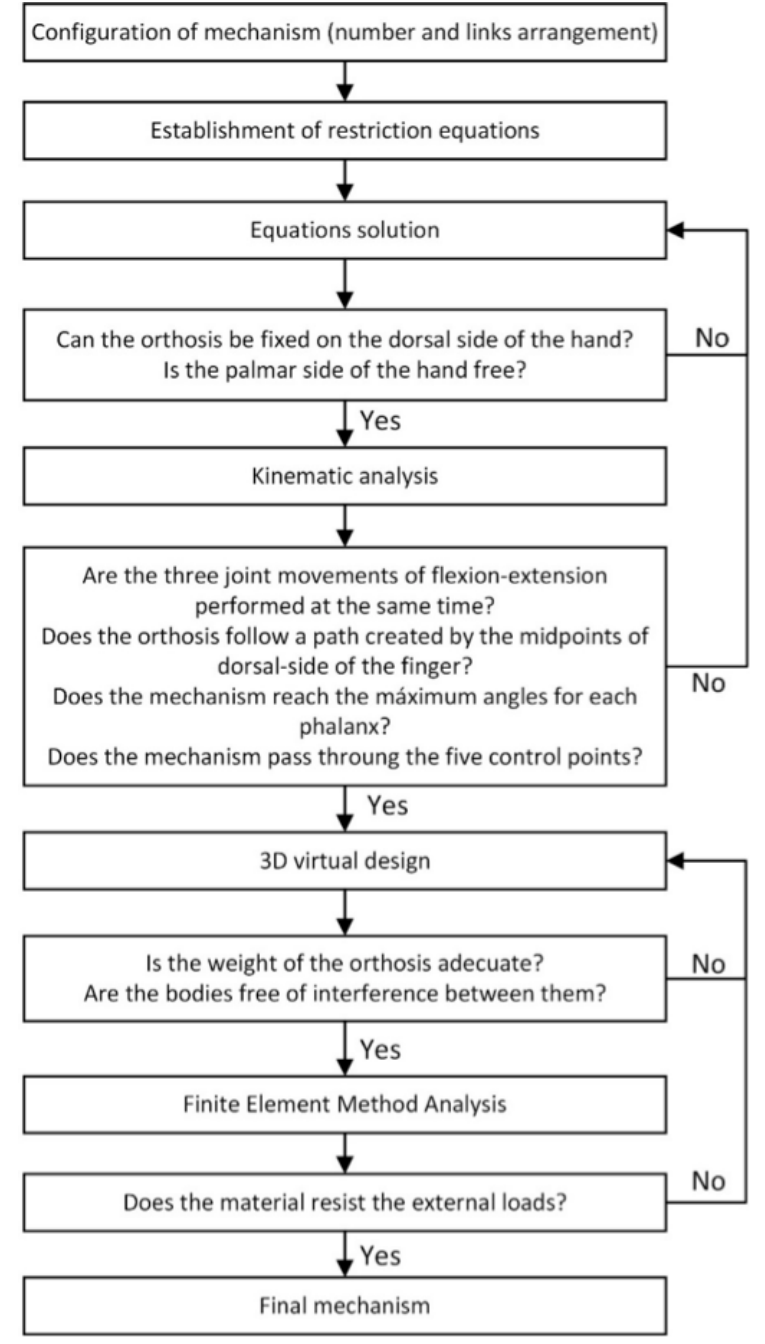

FIGURE 7. Optimal design process.

The virtual design of the optimal orthosis we are interested in is presented below.

\section{Virtual Design and Prototype Manufacturing}

Values obtained through the synthesis are actually in 2D, a Computer-Aided Design software was used to make a $3 \mathrm{D}$ virtual model, in which the rest of all design factors is considered. The virtual model of the orthosis is presented in Figure 8. As the reader can see, our prototype will be placed on the dorsal side of the hand and easily be adapted to any of the fingers. The most important feature of the 3D model is that there should be no interference between any of its components, during the all flexion-extension movement. 


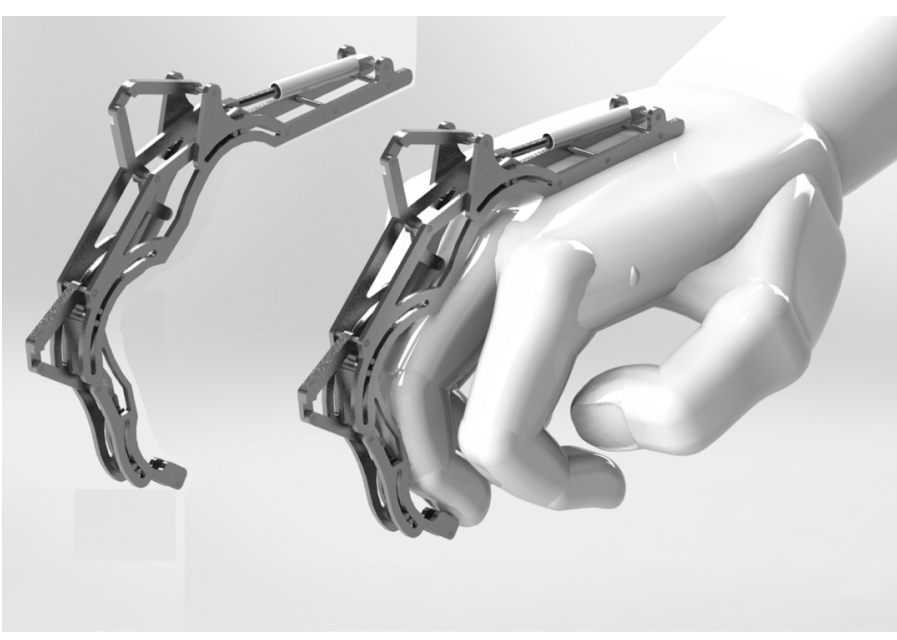

FIGURE 8. Virtual model of the orthosis mechanism.

All links of the mechanism were manufactured using a mini 3-axis CNC mill. All the joints were made using cylinders of steel commercial of $2 \mathrm{~mm}$ of diameter pressure-mounted. Clearance of mobile parts are approximately $0.1 \mathrm{~mm}$.

Figure 9 shows our first orthosis prototype in a fully extended position. The mechanism weight is $0.3531 \mathrm{~N}$ (without actuator), it has a length of $16 \mathrm{~cm}$ and it is 3.2 $\mathrm{cm}$ high; therefore, the size and weight are adequate to be used by a person during all day. A possible actuator can be a standard miniature linear motor, which must be mounted between the points $\mathrm{a}_{0}$ and $\mathrm{a}_{1}$.

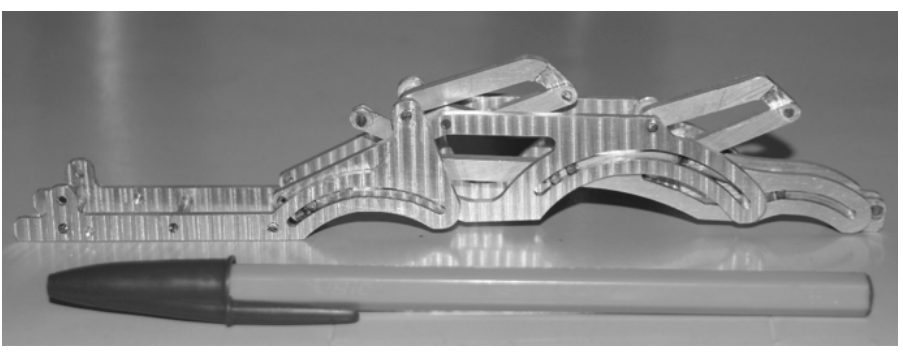

FIGURE 9. Prototype of the finger orthosis.

Figure 10 shows three pictures of our first orthosis prototype mounted on the middle finger of a human hand. As the reader can see, the orthosis is placed only on the dorsal side of the hand, this featured permits the user to perform the ADL without orthosis interference.

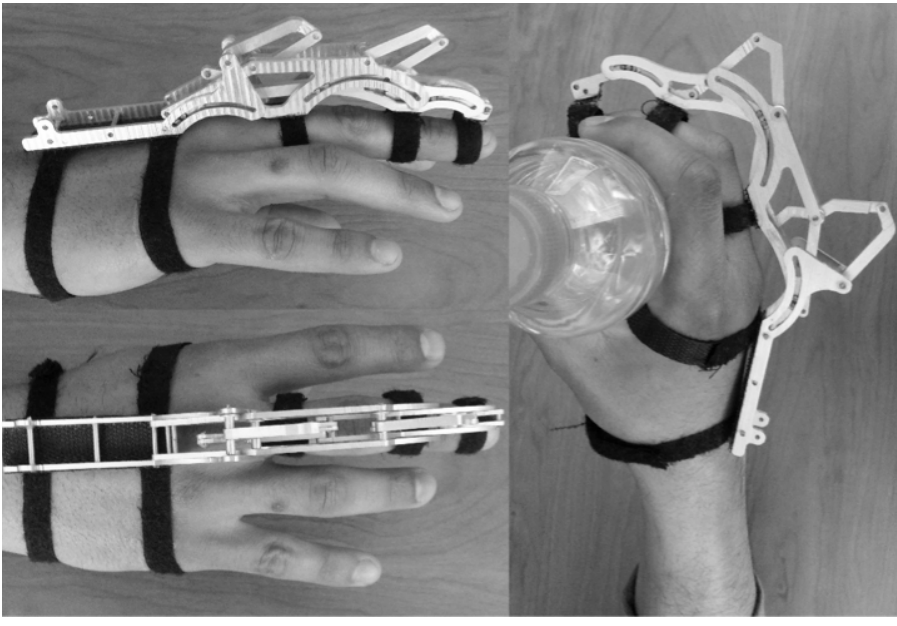

FIGURE 10. First prototype mounted on a middle finger.

\section{CONCLUSIONS}

In this paper a novel mechanical design of a finger orthosis is presented. An optimal synthesis of this orthosis is performed, necessary to satisfy all design factors. The design process is iterative because with the synthesis alone it is not possible to ensure that all requirements are satisfied. The final mechanism has 12 rigid links and 1 degree of freedom, that make possible to flex the three phalanxes at the same time and to activate a greater amount of muscles of the finger; to the best knowledge of the authors, for a finger orthosis these features have not been reported until now.

Three semicircular sliders are used with a new and simple way to synthesize them. We found that this element type, unlike straight sliders, reduce considerably the mechanism size for applications with semicircular movements. A first physical prototype has been manufactured to perform experimental tests as future work.

Mechanism synthesis is performed considering the size of an adult male between 18 and 64 years old, within the percentile 50 of the Mexico City's population. All the orthosis movements considered in this project are based on a natural finger movement; therefore, it is possible to replicate the same mechanism for others fingers, even for others hand sizes, it is 
only necessary to make an adjustment on the scale of each element. The size and weight of the final prototype are adequate to be used by a person during a common day. The mechanism does not interfere with the palmar side of the hand; therefore, the user can perform the Activities of the Daily Living while is being rehabilitated.

\section{FUNDING}

This research was funded by Secretaría de Educación Pública (SEP) and Consejo Nacional de Ciencia y Tecnología (CONACYT) via SEP-CONACYT project No. 3869 "Diseño de ortesis activa de mano". The authors thank the Universidad Autónoma del Estado de México (UAEM) for managing the research funds. 


\section{REFERENCIAS}

[1] Instituto Nacional de Estadística, Geografía e Informática (INEGI) [database on internet]. Discapacidad en México [cited 2014 oct 21]. Available form: www.inegi.org.mx/.

[2] Schabowsky CN, Godfrey SB, Holley RJ, Lum PS. Development and pilot testing of HEXORR: Hand EXOskeleton Rehabilitation Robot. J Neuroeng Rehabil. 2010;7(36). https://dx.doi.org/10.1186/17430003-7-36

[3] Moromugi S, Ishimatsu T, Matsui H, Ikeda T, Mizuta M, Koga T, et al. An electrical prehension orthosis operated through activity of mastication muscle. In: Proc of SICE Annual Conference. Taipei, Taiwan. 2010; p. 2030-2033

[4] America Hear Association [www.heart.org]. New statistics show one of every three U.S. deaths caused by cardiovascular disease. Dallas; c2015. [updated 2017 Aug 16]; [about 2 screens]. Available from: https://goo.gl/l77qsF

[5] Chae J, Hart R. Intramuscular hand neuroprosthesis for chronic stroke survivors. Neurorehabil Neural Repair. 2003;17. pp. 109-117. https://doi.org/10.1177/0888439003017002005

[6] Chae J, Yang G, Park BK, Labatia I. Muscle weakness and cocontraction in upper limb hemiparesis: relationship to motor impairment and physical disability. Neurorehabil Neural Repair. 2002;16. pp. 241-248. https://doi.org/10.1177/154596830201600303

[7] Cruz EG, Waldinger HC, Kamper DG. Kinetic and kinematic workspaces of the index, finger following stroke. Brain. 2005;128. pp. 1112-1121. https://dx.doi.org/10.1093/brain/awh432

[8] Jones CL, Wang F, Morrison R, Sarkan N, Kamper DG. Design and Development of the Cable Actuated Finger Exoskeleton for Hand Rehabilitation Following Stroke. In: IEEE/ASME Transactions on Mechatronics. 2014;19(1), pp. 131-140. https://dx.doi.org/10.1109/ TMECH.2012.2224359

[9] Colombo R, Pisano F, Micera S, Mazzone A, Delconte C, Carrozza MC, et al. Robotic techniques for upper limb evaluation and rehabilitation of stroke patients. IEEE T Neur Sys Reh. 2005;13. pp. 311323. https://dx.doi.org/10.1109/TNSRE.2005.848352

[10] Tong KY, Hu XL. Service Robotics: Robot-Assisted Training for Stroke Rehabilitation. In Service Robotics. Vienna, Austria: I-Tech Education and Publishing. 2008. https://dx.doi.org/10.5772/6062

[11] Takahashi CD, Der-Yeghiaian L, Le V, Motiwala RR, Cramer SC. Robot-based hand motor therapy after stroke. Brain. 2008;131. pp. 425-437. https://doi.org/10.1093/brain/awm311

[12] Hu XL, Tong RK, Ho NSK, Xue JJ, Leondard SW. Wrist Rehabilitation Assisted by an Electromyography-Driven Neuromuscular Electrical Stimulation Robot After Stroke. Neurorehabil Neural Repair. 2015;29(8). pp. 767-776. https://dx.doi. org/10.1177/1545968314565510

[13] Adamovich SV, Fluet GG, Mathai A, Qiu Q, Lewis J, Merians AS. Design of a complex virtual reality simulation to train finger motion for persons with hemiparesis: a proof of concept study. J Neuroeng Rehabil. 2009;6(28). pp. 1-10. https://dx.doi. org/10.1186/1743-0003-6-28

[14] Sarakoglou I, Kousidou S, Tsagarakis NG, Caldwell DG. Exoskeleton-Based Exercisers for Disabilities of the Upper Arm and Hand. In Sashi S Kommu editor. Rehabilitation Robotics. I-Tech Education and Publishing. 2007. p. 499-522. https://dx.doi. org/10.5772/5177
[15] Ho NSK, Tong KY, Hu XL, Fung KL, Wei XJ, Rong W, et al. An EMGdriven exoskeleton hand robotic training device on chronic stroke subjects: task training system for stroke rehabilitation. In IEEE Int Conf Rehabil Robot. Zurich, Switzerland. 2011. https://dx.doi. org/10.1109/ICORR.2011.5975340

[16] Chiri A, Giovacchini F, Vitiello N, Cattin E, Roccella S, Vecchi F, Carrozza MC. HANDEXOS: Towards an exoskeleton device for the rehabilitation of the hand. In: Intelligent Robots and Systems, IROS. IEEE/RSJ International Conference on. MO, USA. 2009. pp. 1106-1111. https://dx.doi.org/10.1109/IROS.2009.5354376

[17] Patar MN, Komeda T, Low CY, Mahmud J. System integration and control of finger orthosis for post stroke rehabilitation. In 2nd International Conference on System-Integrated Intelligence: Challenges for Product and Production Engineering. 2014. pp. 755764. http://dx.doi.org/10.1016/j.protcy.2014.09.048

[18] Rosati G, Cenci F, Boschetti G, Zanotto D, Masiero S. Design of a single-dof active hand orthosis for neurorehabilitation. In: IEEE 11th International Conference on Rehabilitation Robotics. Kyoto, Japan. pp. 160-166. 2009. https://doi.org/10.1109/ ICORR.2009.5209552

[19] Lambercy O, Schröder D, Zwicker S, Gassert R. Design of a thumb exoskeleton for hand rehabilitation. In: Proc. International Convention on Rehabilitation Engineering and Assistive Technology. 2013.

[20] Sooraj R., Akshay N., Jeevan T.G., Bhavani R.R., International Journal of Engineering and Technology. Design and Analysis of a Parallel Haptic Orthosis for Upper Limb Rehabilitation, 2013.

[21] Tjahyono AP et al. A fivefingered hand exoskeleton driven by pneumatic artificial muscles with novel polypyrrole sensors. Ind. Robot. 2013;40(3). pp. 251-260. http://dx.doi. org/10.1108/01439911311309951

[22] Zhang F, Hua L, Fu Y, Chen H, Wang S. Design and development of a hand exoskeleton for rehabilitation of hand injuries. Mech Mach Theory. 2014;73. pp. 103-116. https://dx.doi.org/10.1016/j.mechmachtheory.2013.10.015

[23] Sandoval-González O, Jacinto-Villegas J, Herrera-Aguilar I, Portillo-Rodiguez O, Tripicchio P, Hernandez-Ramos M, et al. Design and Development of a Hand Exoskeleton Robot for Active and Passive Rehabilitation. Int J Adv Robot Syst. 2016;13(66). https://dx.doi.org/10.5772/62404

[24] Leonardis D, Barsotti M, Loconsole C, Solazzi M, Troncossi M, Mazzotti C, et al. An EMG-controlled robotic hand exoskeleton for bilateral rehabilitation. In: IEEE Transactions on Haptics. 2015;8(2). pp. 140-151. https://doi.org/10.1109/TOH.2015.2417570

[25] Norsinnira ZA, Hiroshi Y. Anthropomorphic finger with optimized geometric parameters for pinching and grasping tasks. Mech Mach Theory. 2012;49. pp. 52-66. https://dx.doi.org/10.1016/j.mechmachtheory.2011.11.005

[26] Bataller A, Cabrera JA, Clavijo M, Castillo JJ. Evolutionary synthesis of mechanisms applied to the design of an exoskeleton for finger rehabilitation. Mech Mach Theory. 2016;105. pp. 31-43. https:/l dx.doi.org/10.1016/j.mechmachtheory.2016.06.022

[27] Battezzato A. Towards an underactuated finger exoskeleton: An optimization process of a two-phalange device based on kinetostatic analysis. Mech Mach Theory. 2014;78. pp. 116-130. https:// dx.doi.org/10.1016/j.mechmachtheory.2014.03.007 
[28] Battezzato A. Kinetostatic analysis and design optimization of an n-finger underactuated hand exoskeleton. Mech Mach Theory. 2015;88. pp. 86-104. https://dx.doi.org/10.1016/i.mechmachtheory.2014.12.007

[29] Gezgin E, Chang PH, Akhan AF. Synthesis of a Watt II six-bar linkage in the design of a hand rehabilitation robot. Mech Mach

Theory. 2016;104. pp. 177-189. https://dx.doi.org/10.1016/j.mechmachtheory.2016.05.023
[30] Santiago AV, Valenzuela IB. Ergonomía de miembro superior [dissertation]. Mexico: Universidad Nacional Autónoma de México. 2005.

[31] Cynthia CN, Joyce W. Upper-Extremity Testing. Measurement Of Joint Motion: A Guide To Goniometry. 2016.

[32] Suh CH, Radcliffe CW. The Displacement Matrix in Kinematics. Kinematics and Mechanisms Design. John Wiley; 1978. 